\title{
E-Assessment in Mathematical Sciences (EAMS) Conference
}

Chris Graham, School of Mathematics \& Statistics, Newcastle University, Newcastle, U.K. Email: christopher.graham@ncl.ac.uk

Christian Lawson-Perfect, School of Mathematics \& Statistics, Newcastle University, Newcastle, U.K. Email: christian.perfect@ncl.ac.uk

EAMS Conference Organisers

The inaugural E-Assessment in Mathematical Sciences (EAMS) conference was held in September 2016 at Newcastle University. This two-day conference brought together researchers and practitioners in the field of mathematical e-assessment and was attended by over 70 delegates from all corners of the globe. Motivated by a desire to bring together projects and bubbles of development around the world, around 25 speakers gave a mixture of presentations and workshops.

The conference was opened with a keynote talk by Christian Lawson-Perfect (Newcastle University), who spoke about the student user experience with e-assessment. Other keynote speakers were Mike Gage (University of Rochester), founding developer of the WeBWorK system, Chris Sangwin (University of Edinburgh), who explored the automatic assessment of proof, and Sally Jordan (The Open University), who closed the conference with a talk encouraging delegates to reflect on their own experiences of e-assessment and a look ahead to the future of this field.

Speakers travelled from as far as Japan and South Africa to share their experiences, with insightful talks covering topics such as: flipped classrooms, distant learning, the transition to higher education, applications and development of e-assessment tools and mathematical input interfaces.

As well as the conference proceedings herein, slides and screencasts have been made available on the EAMS conference website via eams.ncl.ac.uk. 